\title{
RYR1 Mutations Are a Common Cause of Congenital Myopathies with Central Nuclei
}

\author{
J.M. Wilmshurst, $\mathrm{MD},{ }^{1}$ S. Lillis, $\mathrm{BSc}^{2} \mathrm{H}$. Zhou, $\mathrm{PhD},{ }^{3} \mathrm{~K}$. Pillay, $\mathrm{MBChB},{ }^{4}$ \\ H. Henderson, PhD, ${ }^{5}$ W. Kress, PhD, ${ }^{6}$ C.R. Müller, PhD, ${ }^{6}$ A. Ndondo, MBBS, ${ }^{1}$ \\ V. Cloke, BSc, ${ }^{2}$ T. Cullup, BSc, ${ }^{2}$ E. Bertini, MD, ${ }^{7}$ C. Boennemann, $\mathrm{PhD}^{8}$ V. Straub, PhD, ${ }^{9}$ \\ R. Quinlivan, MD, ${ }^{10}$ J.J. Dowling, PhD, ${ }^{11}$ S. Al-Sarraj, MD, ${ }^{12}$ S. Treves, $P h D,{ }^{13}$ \\ S. Abbs, PhD, ${ }^{2}$ A.Y. Manzur, MBBS, ${ }^{3}$ C.A. Sewry, PhD, ${ }^{3,10}$ F. Muntoni, MD, ${ }^{3}$ \\ and $\mathrm{H}$. Jungbluth, $\mathrm{MD}, \mathrm{PhD}^{14,15}$
}

Objective: Centronuclear myopathy (CNM) is a rare congenital myopathy characterized by prominence of central nuclei on muscle biopsy. CNM has been associated with mutations in MTM1, DNM2, and BIN1 but many cases remain genetically unresolved. RYR1 encodes the principal sarcoplasmic reticulum calcium release channel and has been implicated in various congenital myopathies. We investigated whether RYR1 mutations cause CNM.

Methods: We sequenced the entire RYR1 coding sequence in 24 patients with a diagnosis of CNM from South Africa $(n=14)$ and Europe $(n=10)$ and identified mutations in 17 patients. The most common genotypes featured compound heterozygosity for RYR1 missense mutations and mutations resulting in reduced protein expression, including intronic splice site and frameshift mutations.

Results: The high incidence in South African patients $(n=12 / 14)$ in conjunction with recurrent $R Y R 1$ mutations associated with common haplotypes suggested the presence of founder effects. In addition to central nuclei, prominent histopathological findings included (often multiple) internalized nuclei and type 1 fiber predominance and hypotrophy with relative type 2 hypertrophy. Although cores were not typically seen on oxidative stains, electron microscopy revealed subtle abnormalities in most cases. External ophthalmoplegia, proximal weakness, and bulbar involvement were prominent clinical findings.

Interpretation: Our findings expand the range of RYR1-related phenotypes and suggest RYR1 mutations as a common cause of congenital myopathies with central nuclei. Corresponding to recent observations in X-linked CNM, these findings indicate disturbed assembly and/or malfunction of the excitation-contraction machinery as a key mechanism in CNM and related myopathies.

Cento entronuclear myopathy (CNM) is a genetically heterogeneous condition characterized by prominence of central nuclei on muscle biopsy and clinical features

ANN NEUROL 2010;68:717-726

of a congenital myopathy. ${ }^{1}$ Mutations in the myotubularin (MTM1) gene ${ }^{2}$ have been identified in the majority of males with the severe X-linked recessive form (or

View this article online at wileyonlinelibrary.com. DOI: 10.1002/ana.22119

Received Feb 25, 2010, and in revised form Jun 7, 2010. Accepted for publication Jun 7, 2010.

Address correspondence to Dr Heinz Jungbluth, Department of Clinical Neurosciences, IOP, King's College London, and Department of Paediatric Neurology, Evelina Children's Hospital, St Thomas' Hospital, Lambeth Palace Road, London SE1 7EH, UK. E-mail: Heinz.Jungbluth@gstt.nhs.uk

J.M.W. and S.L. contributed equally to the manuscript.

From the ${ }^{1}$ Department of Paediatric Neurology, School of Child and Adolescent Health, University of Cape Town, Red Cross Children's Hospital, Cape Town, South Africa; ${ }^{2}$ Diagnostics Genetics Laboratory, GSTS Pathology, Guy's Hospital, London, UK; ${ }^{3}$ Dubowitz Neuromuscular Centre, Institute of Child Health, London, UK; ' Department of Paediatric Pathology, School of Child and Adolescent Health, University of Cape Town, Red Cross Children's Hospital, Cape Town, South Africa; ${ }^{5}$ Molecular Genetics Department, University of Cape Town, South Africa; ${ }^{6}$ Institute of Human Genetics, University of Wuerzburg, Biozentrum, Germany; ${ }^{7}$ Unit of Molecular Medicine, Ospedale Bambino Gesù, Rome, Italy; ${ }^{8}$ Department of Paediatric Neurology, Children's Hospital of Philadelphia, Philadelphia, Pennsylvania, USA; ${ }^{9}$ Institute for Human Genetics, International Centre for Life, University of Newcastle upon Tyne, Newcastle upon Tyne, UK; ${ }^{10}$ Centre for Inherited Neuromuscular Disorders, Robert Jones \& Agnes Hunt Orthopaedic Hospital, Oswestry, UK; ${ }^{11}$ Department of Pediatrics, University of Michigan Medical Center, Ann Arbor, Michigan, USA; ${ }^{12}$ Department of Clinical Neuropathology, King's College Hospital, London, UK; ${ }^{13}$ Departments of Anaesthesia and Research, Basel University Hospital, Basel, Switzerland; ${ }^{14}$ Department of Paediatric Neurology, Neuromuscular Service, Evelina Children's Hospital, St Thomas' Hospital, London, UK; ${ }^{15}$ Clinical Neuroscience Division, IOP, King's College, London, UK. 
"myotubular myopathy"), ${ }^{3}$ whereas dominant dynamin 2 (DNM2) mutations ${ }^{4,5,7}$ and recessive amphiphysin 2 (BIN1) mutations ${ }^{6}$ have been implicated in some families with relatively milder phenotypes. A substantial proportion of cases with variable severity remains currently genetically unresolved. ${ }^{8}$ Extraocular muscle involvement is common in all forms of CNM.

The MTM1, DNM2, and BIN1 genes all encode proteins with a role in different aspects of membrane trafficking and remodeling. The skeletal muscle ryanodine receptor (RYR1) gene, encoding the principal sarcoplasmic reticulum (SR) calcium release channel with a crucial role in excitation-contraction coupling (ECC), has been implicated in various neuromuscular phenotypes including the malignant hyperthermia susceptibility (MHS) trait, central core disease (CCD) and subgroups of multi-minicore disease $(\mathrm{MmD}) .{ }^{9}$ There is substantial clinical and histopathological overlap between CNM and $\mathrm{MmD}$ with ophthalmoplegia, ${ }^{10-12}$ but $R Y R 1$ involvement in CNM to date has only been suggested in one isolated patient harboring a single heterozygous missense mutation. ${ }^{13}$ The recent observation of disrupted T-tubule assembly in animal models of myotubular myopathy ${ }^{14,15}$ indicates involvement of molecular regulation of ECC as a potentially important pathogenetic mechanism in CNM.

Here we report evidence for frequent $R Y R 1$ involvement in a large cohort of patients with a diagnosis of $\mathrm{CNM}$ and consistent clinicopathological features.

\section{Patients and Methods}

\section{Patients}

Patients were selected from a cohort of 24 patients from 23 unrelated, nonconsanguineous families with genetically unresolved CNM. RYR1 mutations were identified in 17 patients, 12 from South Africa and five from the United Kingdom and other European countries. Within the South African group, four patients were of indigenous African ancestry and eight were of "mixed" ancestry (referring to people descended from an admixture of Caucasian, Khoisan, Malay, Javanese Sumatran, and black African ancestries). Within the European group, all patients were Caucasian. Detailed histories for each of the 17 patients are provided in Supporting File S1.

\section{Muscle Histology}

All patients had muscle biopsies except one boy (Patient 15) in whom the diagnosis was made based on clinical features identical to those of his older sister (Patient 14). We reviewed the standard histological (hematoxylin and eosin [H\&E]; Gomori trichrome [GT]; periodic acid-Schiff [PAS]) and histochemical (nicotinamide adenosine dinucleotide-tetrazolium reductase [NADH-TR]; myosin adenosine triphosphatase [ATPase], preincubated at $\mathrm{pH}$ 9.4, 4.6, and 4.3; cytochrome $\mathrm{C}$ oxidase
[COX]) stains in all patients. In addition, electron microscopy images were available for review from 14 biopsies. All muscle biopsies had been taken from the quadriceps, with the exception of Patient 1 (deltoid). Longitudinal evolution of findings could be evaluated in three patients (Patients 3, 16, 17) who had more than one biopsy. No parental biopsy samples were available.

The number of fibers with nuclear internalization (ie, nuclei appearing underneath the sarcolemma anywhere within the cytoplasm) and nuclear centralization (ie, nuclei in the geometric center of the fiber) were determined on H\&E-stained sections based on a count of at least 200 fibers at a magnification of $\times 100$.

\section{Molecular Genetic Studies}

The triplet repeat expansion associated with myotonic dystrophy, histopathologically similar to CNM, was excluded in all patients prior to RYRI screening. MTMI mutations were excluded by direct sequencing in the most severely affected male (Patient 13) and all females. In Patients 1, 2, 4, 12, and 13, dynamin 2 (DNM2) mutations were also excluded. In addition, Patient 13 was screened for ACTA1 and TPM3 mutations previously associated with congenital fiber type disproportion (CFTD) ${ }^{16,17}$ because of suggestive histopathological features.

The entire coding regions (exons 1-106) of the RYRI gene including splice sites were screened at the genomic level in all patients and at the RNA level in patients 16 and 17 as previously described. ${ }^{18}$ Family members of the probands found to carry RYR1 mutations were investigated for the presence of the mutation identified by direct sequencing where DNA was available.

\section{Haplotyping at the RYR1 Locus}

Haplotyping of the unrelated patients carrying any of three recurrent RYRI mutations identified was carried out using a panel of highly polymorphic microsatellite repeat markers located in and around the RYRI locus. Those included the intragenic marker RYR1_IVS89 and flanking markers D19S224, D19S896, D19S570, D19S220, 18xAC, D19S897, D19S422, D19S881, 21xGT, D19S47, D19S200 (recombination error rate $<1 \%$ ). The markers were separated by size into two multiplexes and a tagged primer approach was used for polymerase chain reaction (PCR) amplification. Electrophoresis of the products on the ABI3730 was analyzed using the Genemarker software package (supplied by Softgenetics, State College, PA).

\section{RyR1 Protein Quantification}

Western blotting of RyR1 protein extracted from patient muscle and densitometric analysis was performed as described previously. $^{18}$ 


\begin{tabular}{|c|c|c|c|c|c|c|c|c|c|c|c|c|c|}
\hline No. & Age & Sex & Origin & Onset & Presentation & Sitting & Walking & $\begin{array}{l}\text { Motor } \\
\text { Function }\end{array}$ & Ocular & Weakness & Respiration & $\begin{array}{l}\text { Bulbar } \\
\text { Involvement }\end{array}$ & Scoliosis \\
\hline 1 & $19 y$ & $\mathrm{~F}$ & SA & Birth & $\begin{array}{l}\text { RFM, } \\
\text { Hypotonia, } \\
\text { Feeding diff. }\end{array}$ & $13 / 12$ & $23 / 12$ & Walking & $\begin{array}{l}\text { EOM, } \\
\text { ptosis }\end{array}$ & Proximal & RTI & Mild & $\mathrm{N}$ \\
\hline 2 & $9 \mathrm{y}$ & $\mathrm{F}$ & SA & Birth & Hypotonia & $18 / 12$ & - & Sitting & EOM & $\begin{array}{l}\text { Proximal, } \\
\text { axial }\end{array}$ & RTI & $\begin{array}{l}\text { Marked } \\
\text { (gastrostomy) }\end{array}$ & $\begin{array}{l}\mathrm{Y} \\
\text { (fusion) }\end{array}$ \\
\hline 3 & $8 \mathrm{y}$ & M & SA & Birth & Hypotonia & $11 / 12$ & $18 / 12$ & Walking & EOM & Proximal & - & - & $\mathrm{N}$ \\
\hline 4 & $13 y$ & $\mathrm{~F}$ & SA & Birth & $\begin{array}{l}\text { RFM, } \\
\text { Hypotonia }\end{array}$ & ND & ND & Walking & $\begin{array}{l}\text { EOM, } \\
\text { ptosis }\end{array}$ & Proximal & RTI & - & $\mathrm{N}$ \\
\hline 5 & $15 y$ & M & SA & Birth & $\begin{array}{l}\text { RFM, Hypotonia, } \\
\text { Feeding diff. }\end{array}$ & $11 / 12$ & - & Sitting & $\begin{array}{l}\mathrm{EOM}, \\
\text { ptosis }\end{array}$ & Proximal & RTI & Mild & $\mathrm{N}$ \\
\hline 6 & $7 y$ & M & SA & Birth & $\begin{array}{l}\text { RFM, } \\
\text { Hypotonia, } \\
\text { Feeding diff. }\end{array}$ & $18 / 12$ & - & Sitting & $\begin{array}{l}\text { EOM, } \\
\text { ptosis }\end{array}$ & Proximal & RTI & Mild & $\mathrm{N}$ \\
\hline 7 & $10 y$ & M & SA & Birth & RFM, Hypotonia & ND & ND & Sitting & EOM & Proximal & - & - & $\mathrm{N}$ \\
\hline 8 & $8 \mathrm{y}$ & M & SA & Birth & $\begin{array}{l}\text { RFM, Hypotonia, } \\
\text { Feeding diff. }\end{array}$ & $11 / 12$ & - & Sitting & $\begin{array}{l}\text { EOM, } \\
\text { ptosis }\end{array}$ & Proximal & - & Mild & $\mathrm{N}$ \\
\hline 9 & $14 y$ & $\mathrm{~F}$ & SA & Birth & RFM, Hypotonia & $12 / 12$ & - & Sitting & $\begin{array}{l}\mathrm{EOM}, \\
\text { ptosis }\end{array}$ & $\begin{array}{l}\text { Proximal, } \\
\text { axial }\end{array}$ & RTI & Mild & $\mathrm{Y}$ \\
\hline 10 & $8 \mathrm{y}$ & M & SA & Birth & $\begin{array}{l}\text { RFM, PHD, } \\
\text { Hypotonia, }\end{array}$ & $12 / 12$ & - & Sitting & $\begin{array}{l}\text { EOM, } \\
\text { ptosis }\end{array}$ & $\begin{array}{l}\text { Proximal, } \\
\text { axial }\end{array}$ & RTI & Mild & $\mathrm{N}$ \\
\hline 11 & $5 y$ & M & SA & Birth & Hypotonia & $12 / 12$ & - & Sitting & EOM & $\begin{array}{l}\text { Proximal, } \\
\text { axial }\end{array}$ & RTI & Mild & $\mathrm{N}$ \\
\hline 12 & $13 y$ & $\mathrm{~F}$ & SA & Birth & Hypotonia & ND & ND & Walking & EOM & $\begin{array}{l}\text { Proximal, } \\
\text { Distal LL }\end{array}$ & RTI & - & $\mathrm{N}$ \\
\hline 13 & $2 y$ & M & Poland & Birth & $\begin{array}{l}\text { RFM, Hypotonia, } \\
\text { Feeding diff. }\end{array}$ & - & - & - & EOM & $\begin{array}{l}\text { Proximal, } \\
\text { axial }\end{array}$ & $\begin{array}{l}\text { Ventilated at birth } \\
\text { Tracheostomy }\end{array}$ & $\begin{array}{l}\text { Marked } \\
\text { (gastrostomy) }\end{array}$ & $\mathrm{Y}$ \\
\hline 14 & $4 y$ & $\mathrm{~F}$ & UK & Birth & $\begin{array}{l}\text { RFM, Hypotonia, } \\
\text { Feeding diff. }\end{array}$ & $13 / 12$ & $23 / 12$ & Walking & EOM & $\begin{array}{l}\text { Proximal, } \\
\text { axial }\end{array}$ & Ventilated at birth & Moderate & $\mathrm{N}$ \\
\hline 15 & $2 y$ & M & UK & Birth & $\begin{array}{l}\text { RFM, Hypotonia, } \\
\text { Feeding diff. }\end{array}$ & $11 / 12$ & $19 / 12$ & Walking & - & $\begin{array}{l}\text { Proximal, } \\
\text { axial }\end{array}$ & Ventilated at birth & $\begin{array}{l}\text { Marked } \\
\text { (gastrostomy) }\end{array}$ & $\mathrm{N}$ \\
\hline 16 & $23 y$ & $\mathrm{~F}$ & Italy & Birth & $\begin{array}{l}\text { Hypotonia, } \\
\text { Feeding diff. }\end{array}$ & ND & $20 / 12$ & Walking & EOM & $\begin{array}{l}\text { Proximal, } \\
\text { Distal LL }\end{array}$ & - & - & $\mathrm{N}$ \\
\hline 17 & $17 y$ & $\mathrm{~F}$ & Germany & Childhood & Proximal weakness & $6 / 12$ & $14 / 12$ & Walking & EOM & $\begin{array}{l}\text { Proximal, } \\
\text { axial }\end{array}$ & - & - & $\mathrm{N}$ \\
\hline
\end{tabular}

\section{Results}

\section{Clinical Findings}

The reviewed main clinical findings are in Table 1 and Figure 1. Eight patients were female and nine were male. Median age at last follow-up was 9 years with a range of 2 years to 23 years. Eleven patients had reduced in utero movements and all except one (Patient 17) presented from birth with hypotonia and weakness. All children but one (Patient
13) attained unsupported sitting but only eight children had attained independent walking at the time of last followup. There was no cognitive involvement. Bulbar involvement leading to feeding difficulties was common; many patients required intermittent nasogastric tube feeding in the neonatal period and three patients subsequently required a gastrostomy. Respiratory tract infections were frequent but in most patients reduced over time. One of the three 


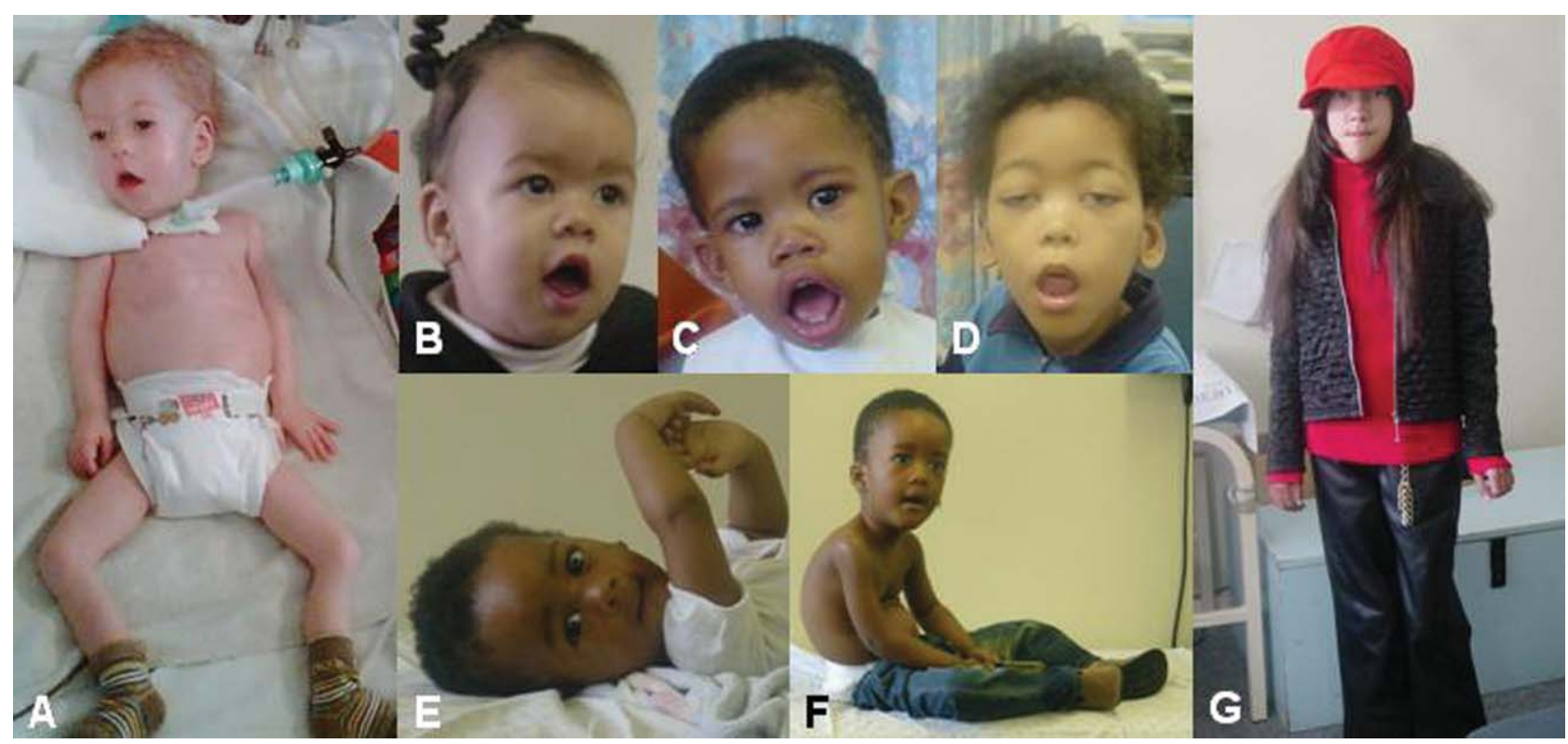

FIGURE 1: Phenotypical variability associated with RYR1-related congenital myopathy with central nuclei. (A) Severely affected 14-month-old boy with ptosis, extraocular muscle involvement, hypotonia, and permanent ventilatory requirement (Patient 13). (B-D) Typical facial aspect with inverted V-shaped mouth and marked ptosis, almost resembling individuals with myotonic dystrophy (Patients 3, 8, 7). (E-F) Developmental progression in Patient 6 from infancy to 2 years of age, just sitting without support but unable to walk. (G) Patient 1 in her teens with only mild difficulties despite profound hypotonia and bulbar involvement in infancy. [Color figure can be viewed in the online issue, which is available at wileyonlinelibrary.com.]

patients who required intubation and ventilation at birth (Patients 13, 14, 15) subsequently developed a persistent ventilatory requirement necessitating a tracheostomy. Patients had similar phenotypic appearances (Fig 1) with a myopathic facies with inverted V-shaped mouth, external ophthalmoplegia with or without ptosis, hypotonia, proximal weakness, and reduced or absent deep tendon reflexes. The further course in most patients was characterized by slow improvement of muscle strength and, in particular, bulbar and respiratory involvement. No malignant hyperthermia $(\mathrm{MH})$ reactions were recorded but none of the patients had been formally assessed by in vitro contracture testing (IVCT).

\section{Muscle Histology}

We reviewed all available muscle biopsies (Table 2; Fig 2). First muscle biopsies were performed between 2 months and 5 years of age (median age 10.5 months). On the first muscle biopsy, a substantial increase in fibers with nuclear centralization (median 11\%; range 3-30\%) and with nuclear internalization (median 10.5\%; range 3-34\%), often multiple, was present in all patients (Fig 2A). Fibers containing central nuclei were often very small. Mild to moderate increases in fat and/or connective tissues were seen in most cases. In one patient (Patient 17) necklace fibers ${ }^{19}$ were identified as an additional finding. Type 1 predominance (Fig 2B,C) was present in the first muscle biopsy in all patients except Patients 9 and 10. In addition, type 2 hy- pertrophy and fiber type disproportion with type 2 fibers at least $25 \%$ larger than type 1 fibers (Fig 3A-C) was present in 12 biopsies. With stains for oxidative enzymes central accumulation of stain (Fig 2C) was consistent but peripheral halos commonly seen in X-linked myotubular myopathy were only seen in three patients (Patients 5, 14, 17). Radial strands were not observed. None of our patients had corelike structures on the first muscle biopsy but two had a "moth-eaten" appearance with oxidative enzyme stains (Patients 2, 6). Central or minicores developed with age in two out of three patients who had follow-up biopsies later in life (Patients 16,17), but were not a prominent feature. In addition, Z-line streaming was observed on 14 biopsies where electron microscopy was performed and on five of these additional core-like structures were seen (Fig 2D). One patient had unevenness of stain with ATPase reactions on follow-up biopsy at 3.5 years but this was not observed on corresponding oxidative stains (Fig 3A-C).

\section{Molecular Genetic Analysis, RYR1 Haplotyping, and RyR1 Protein Quantification}

The main genetic findings (Supporting File S2) were characterized by compound heterozygosity for RYRI nonsense and missense mutations. Within the South African CNM population, three recurrent RYR1 mutations could be identified: 1) c.5726_5727delAG, p.Glu1909GlyfsX39 (exon 35) always associated with c.9242T $>$ C p.Met3081Thr (exon 63) (n= 2); 2) 


\begin{tabular}{|c|c|c|c|c|c|c|c|c|c|c|}
\hline \multirow[t]{2}{*}{ No. } & \multirow[t]{2}{*}{ Age } & \multirow[t]{2}{*}{ FTD } & \multicolumn{2}{|c|}{ Type 1} & \multicolumn{3}{|c|}{ Nuclei (\%) } & \multirow{2}{*}{$\begin{array}{l}\text { Fatty/ } \\
\text { Connective } \\
\text { Tissue }\end{array}$} & \multirow{2}{*}{$\begin{array}{l}\text { Oxidative } \\
\text { Abnormalities }\end{array}$} & \multirow[t]{2}{*}{ EM } \\
\hline & & & Pred. & Hypo. & cen. & int. & Total & & & \\
\hline 1 & $7 \mathrm{~m}$ & $\mathrm{Y}$ & $\mathrm{Y}$ & $\mathrm{Y}$ & 9 & 3 & 12 & Mild & Central accumulation & Z-line streaming \\
\hline 2 & $2 y$ & $\mathrm{Y}$ & $\mathrm{Y}$ & $\mathrm{Y}$ & 7 & 8 & 15 & Mild & $\begin{array}{l}\text { Central accumulation; } \\
\text { "moth-eaten" fibres }\end{array}$ & $\begin{array}{l}\text { Z-line streaming; } \\
\text { MC, CC }\end{array}$ \\
\hline \multirow[t]{2}{*}{3} & $8 \mathrm{~m}$ & $\mathrm{Y}$ & $\mathrm{Y}$ & $\mathrm{Y}$ & 23 & 24 & 47 & Moderate & Central accumulation & Z-line streaming \\
\hline & $3.5 y$ & $\mathrm{Y}$ & $\mathrm{Y}$ & $\mathrm{Y}$ & 6 & 4 & 10 & Moderate & Central accumulation & $\begin{array}{l}\text { Z-line streaming; } \\
\text { MC }\end{array}$ \\
\hline 4 & $5 y$ & $\mathrm{~N}$ & $\mathrm{Y}$ & $\mathrm{Y}$ & 30 & 12 & 42 & Mild & Central accumulation & Z-line streaming \\
\hline 5 & $13 \mathrm{~m}$ & $\mathrm{~N}$ & $\mathrm{Y}$ & $\mathrm{Y}$ & 8 & 13 & 21 & Moderate & $\begin{array}{l}\text { Central accumulation; } \\
\text { Perinuclear halo }\end{array}$ & $\begin{array}{l}\text { Z-line streaming; } \\
\text { MC }\end{array}$ \\
\hline 6 & $18 \mathrm{~m}$ & $\mathrm{~N}$ & $\mathrm{Y}$ & $\mathrm{Y}$ & 7 & 9 & 16 & Moderate & $\begin{array}{l}\text { Central accumulation; } \\
\text { "moth-eaten" fibres }\end{array}$ & Z-line streaming \\
\hline 8 & $6 \mathrm{~m}$ & $\mathrm{~N}$ & $\mathrm{Y}$ & $\mathrm{Y}$ & 9 & 6 & 15 & Moderate & Central accumulation & Z-line streaming \\
\hline 8 & $7 \mathrm{~m}$ & $\mathrm{Y}$ & $\mathrm{Y}$ & $\mathrm{Y}$ & 20 & 4 & 24 & Normal & Central accumulation & Z-line streaming \\
\hline 9 & $1 y$ & $\mathrm{Y}$ & $\mathrm{N}$ & $\mathrm{Y}$ & 13 & 19 & 22 & Moderate & Central accumulation & Z-band streaming \\
\hline 10 & $9 \mathrm{~m}$ & $\mathrm{Y}$ & $\mathrm{N}$ & $\mathrm{Y}$ & 28 & 34 & 62 & Moderate & Central accumulation & Z-band streaming \\
\hline 11 & $1 y$ & $\mathrm{Y}$ & $\mathrm{Y}$ & $\mathrm{Y}$ & 10 & 4 & 14 & Moderate & Central accumulation & Z-line streaming \\
\hline 12 & $4 y$ & $\mathrm{~N}$ & $\mathrm{Y}$ & $\mathrm{Y}$ & 17 & 21 & 38 & Moderate & Central accumulation & $\begin{array}{l}\text { Z-line streaming; } \\
\text { MC }\end{array}$ \\
\hline 13 & $4 \mathrm{~m}$ & $\mathrm{Y}$ & $\mathrm{Y}$ & $\mathrm{Y}$ & 3 & 6 & 9 & Marked & Central accumulation & - \\
\hline 14 & $3 \mathrm{~m}$ & $\mathrm{~N}$ & $\mathrm{Y}$ & $\mathrm{Y}$ & 4 & 3 & 7 & Mild & $\begin{array}{l}\text { Central accumulation; } \\
\text { Perinuclear halo }\end{array}$ & $\begin{array}{l}\text { Z-line streaming; } \\
\text { MC }\end{array}$ \\
\hline \multirow[t]{2}{*}{16} & $5 y$ & $\mathrm{Y}$ & $\mathrm{Y}$ & $\mathrm{Y}$ & 12 & 22 & 34 & Mild & Normal & - \\
\hline & $12 y$ & $\mathrm{~N}$ & $\mathrm{Y}$ & $\mathrm{N}$ & 21 & 29 & 50 & Moderate & Few cores & - \\
\hline \multirow[t]{2}{*}{17} & $2 \mathrm{~m}$ & $\mathrm{Y}$ & $\mathrm{Y}$ & $\mathrm{Y}$ & 21 & 18 & 39 & Moderate & Central accumulation & - \\
\hline & $8 y$ & $\mathrm{Y}$ & $\mathrm{Y}$ & $\mathrm{Y}$ & 17 & 20 & 37 & Marked & $\begin{array}{l}\text { Central accumulation; } \\
\text { Perinuclear halo; } \\
\text { Few cores }\end{array}$ & - \\
\hline
\end{tabular}

c.8342_8343delTA, p.Ile2781ArgfsX49 (exon 53) always associated with c.11941C $>$ T, p.His3981Tyr (exon 87) $(\mathrm{n}=3$ ); and 3) c.14524G $>$ A, p.Val4842Met (exon 101) always in conjunction with c.10348-6C $>G$ (intron 68) $(\mathrm{n}=11)$. We were able to propose common haplotypes associated with each of the three recurrent RYR1 variants, supporting the presence of founder effects in this cohort (Fig 4).

The common South African exonic c.14524G $>$ A, p.Val4842Met and intronic c.10348-6C $>$ G variations have been reported previously in two severely affected siblings of undeclared ethnicity from Chile. ${ }^{11}$ The paternally inherited c.4024A $>$ G; p.Ser1342Gly and c.8360C $>$ G;
p.Thr2787Ser variations identified in Patient 9 in cis have been reported previously in patients with $\mathrm{CCD}^{20}$ but are also listed on the NCBI SNP database as rs34694816 and rs35180584, respectively. None of the expressed missense mutations was identified in more than 200 predominantly Caucasian control chromosomes. In addition, the most common recurrent RYR1 mutation was not found in more than 200 South African control chromosomes of mixed ethnicity. Parental DNA samples were available from seven families. Although findings in four of those families were compatible with recessive inheritance, in three patients (Patients 11, 16, 17) only one heterozygous RYR1 missense mutation inherited from an asymptomatic 


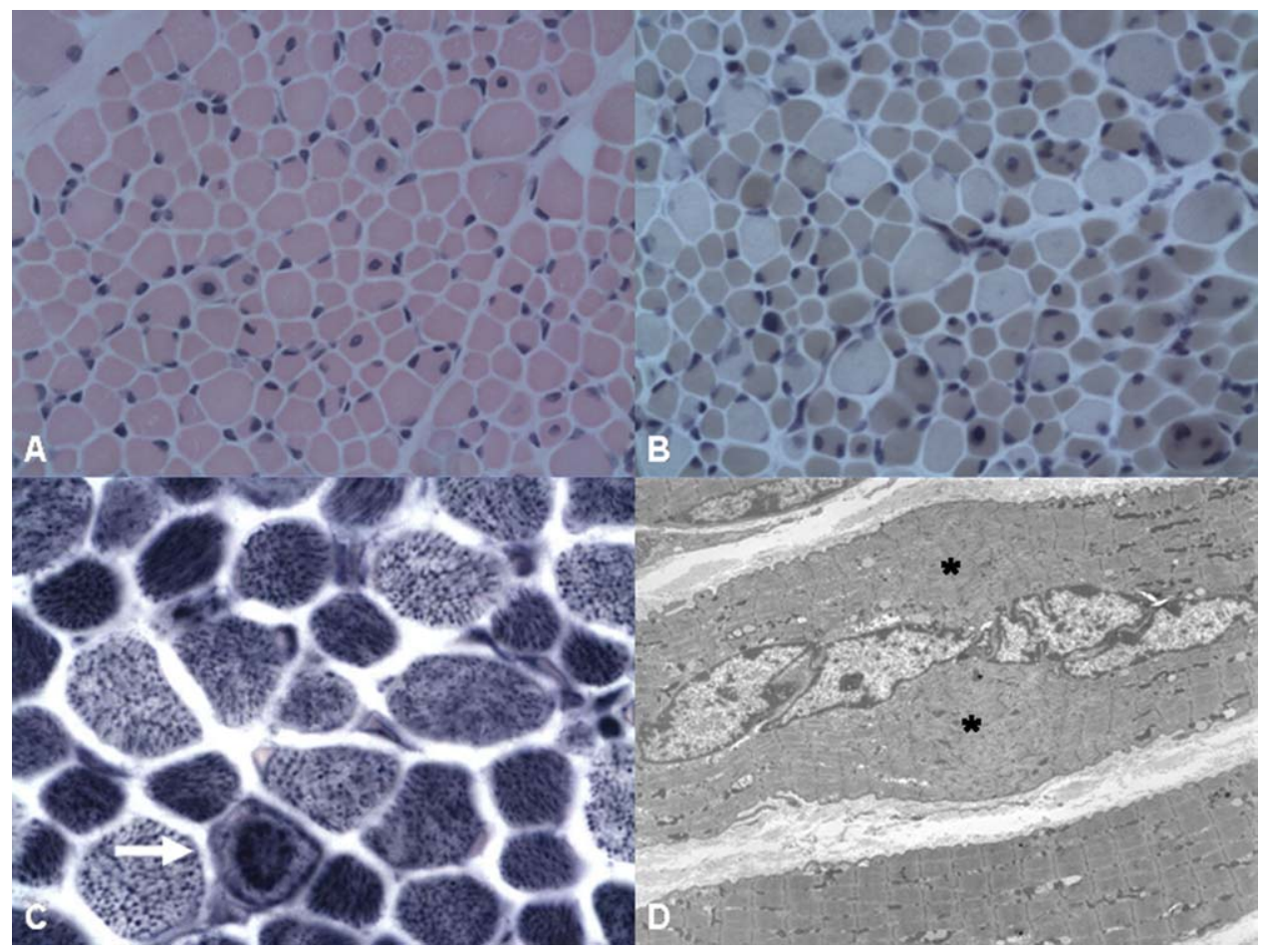

FIGURE 2: Histopathological features of RYR1-related congenital myopathy with central nuclei. Muscle biopsy from Patient 14 performed at 3 months of age. (A) Hematoxylin and eosin (H\&E). On transverse section, there is marked variability in fiber size with a mild increase in endomysial connective tissue and a little adipose tissue. Several smaller fibers contain centralized internal nuclei and there are additional multiple internal nuclei in other fibers. (B) With staining for ATPase after acid preincubation there is a predominance of darker staining hypotrophic type 1 fibers with few larger type 2 fibers. (C) With staining for NADH-TR there is a predominance of smaller high oxidative fibers. One fiber (arrow) shows central accumulation of stain and a perinuclear halo. There are no cores devoid of enzyme activity. (D) Electron microscopy, longitudinal section, showing central nuclei aligned in chains. There is Z-line streaming and minicore formation next to the nuclei (*). [Color figure can be viewed in the online issue, which is available at wileyonlinelibrary.com.]

parent was identified. The molecular basis for the marked phenotypical variability in these families is uncertain.

In addition to a number of RYRI mutations expected to result in premature stop codons, the intronic variant c. $3381+1 \mathrm{G}>\mathrm{A}$ identified in Patient 7 is predicted to introduce a new splice donor site, whereas the c. $8067 \mathrm{G}>$ T substitution found in Patient 13 is predicted to abolish the splice donor site of exon 50. Corresponding to the presence of nonsense mutations, we could demonstrate reduction of the RyR1 protein in Patients 2-6
(Fig 5). However, protein reduction in excess of $50 \%$ in some patients could not be accounted for by the presence of a presumably randomly expressed heterozygous nonsense mutation alone and is likely to reflect an additional and variable effect of the allelic intronic c.10348-6C>G substitution identified in 11 patients. Previous work ${ }^{11}$ suggested that this variation results in the production of an aberrant transcript that includes intron 68 and introduces a premature stop codon (p.His3449ins33fsX54), but that the penetrance of this mutation is incomplete,
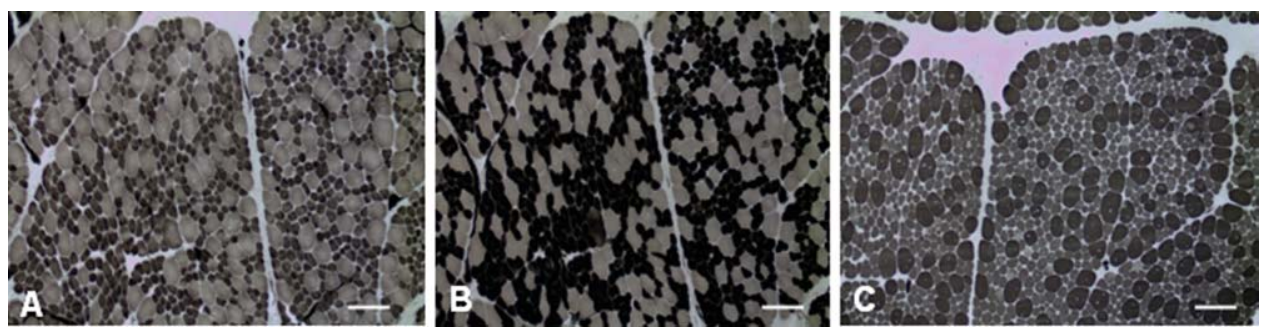

FIGURE 3: (A-C) Repeat muscle biopsy from Patient 3 performed at 3.5 years of age, transverse sections, stained by ATPase preincubated at $\mathrm{pH}$ of (A) 4.3, (B) 4.6, and (C) 9.4. There is a predominance of hypotrophic type 1 fibers (that appear dark with acidic preincubation but light at $\mathrm{pH}$ 9.4) and few hypertrophic type 2 fibers (that appear light with acidic preincubation but dark at $\mathrm{pH}$ 9.4). Fiber size disproportion between type 1 fibers and type 2 fibers is in excess of $25 \%$. There is unevenness of stain in a few fibers. Scale bar $=50 \mu \mathrm{m}$. [Color figure can be viewed in the online issue, which is available at wileyonlinelibrary.com.] 


\begin{tabular}{|l|l|}
\hline Marker & Mb \\
\hline D19S224 & 2.46 \\
\hline D19S896 & 1.51 \\
\hline D19S570 & 1.26 \\
\hline D19S220 & 0.56 \\
\hline 18XAC & 0.27 \\
\hline D19S897 & 0.23 \\
\hline RYR1 & 0.00 \\
\hline RYR1_IVS89 & 0.00 \\
\hline D19S422 & 0.11 \\
\hline D19S881 & 0.29 \\
\hline D19S47 & 1.26 \\
\hline D19S200 & 1.64 \\
\hline
\end{tabular}
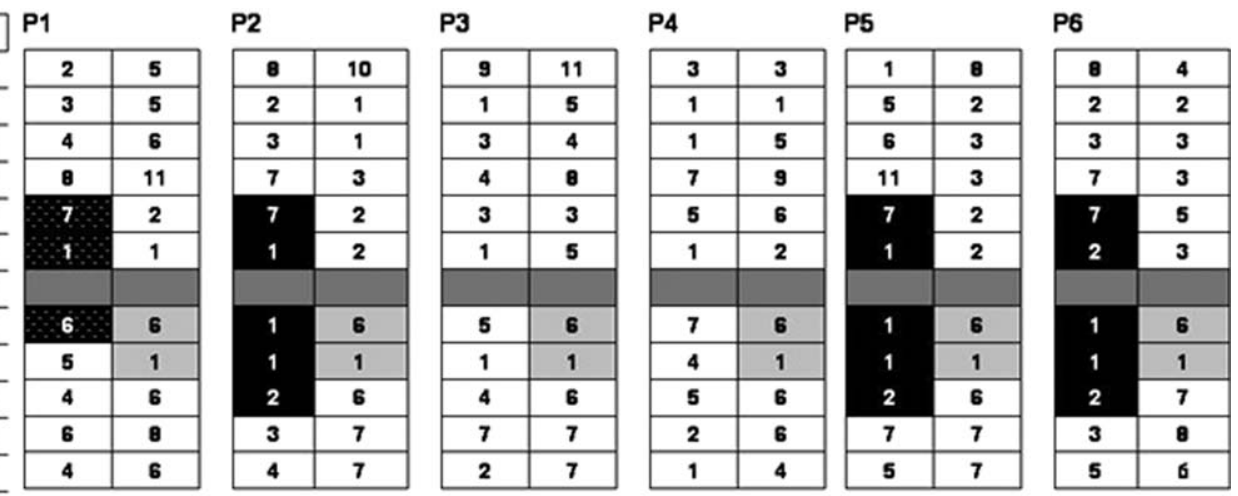

\begin{tabular}{|l|l}
\hline Marker & Mb \\
\hline D19S224 & 2.46 \\
\hline D19S896 & 1.51 \\
\hline D19S570 & 1.26 \\
\hline D19S220 & 0.56 \\
\hline 18XAC & 0.27 \\
\hline D19S897 & 0.23 \\
\hline RYR1 & 0.00 \\
\hline RYR1_IVS89 & 0.00 \\
\hline D19S422 & 0.11 \\
\hline D19S881 & 0.29 \\
\hline D19S47 & 1.26 \\
\hline D19S200 & 1.64 \\
\hline
\end{tabular}
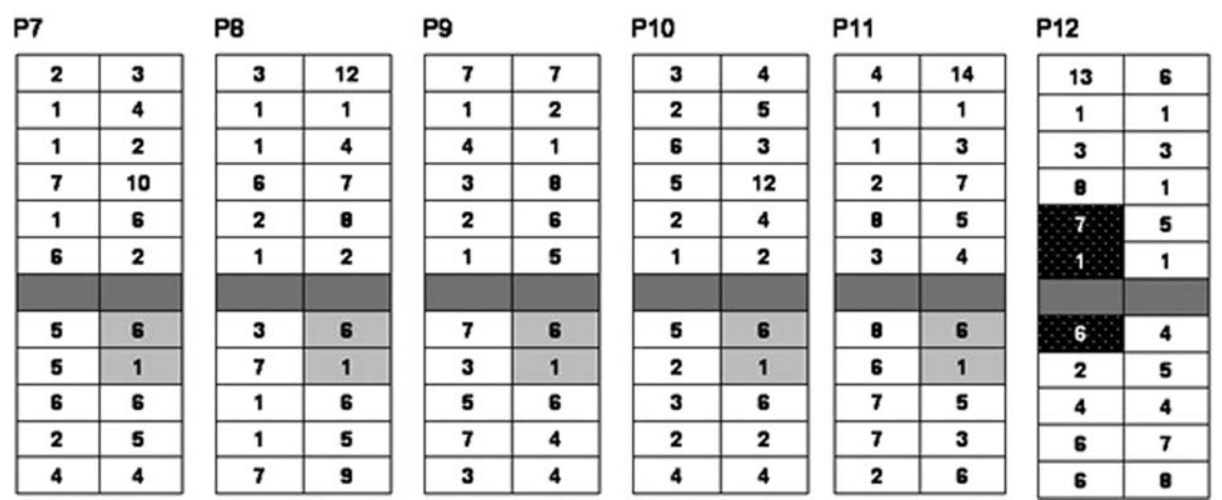

FIGURE 4: Haplotyping at the RYR1 locus demonstrating common haplotypes associated with the three recurrent RYR1 genotypes observed in the South African population. The three common haplotypes associated with specific RYR1 mutations are indicated by differently shaded backgrounds. Patients harboring the intron 68; c.10348-6C>G and the exon 101; c.14524G>A; p.Val4842Met substitutions $(n=11)$ share a common haplotype between polymorphic microsatellite repeat markers RYR1_IVS89 and D19S422 $(0.11 \mathrm{Mb})$ (grey background), patients harboring the exon 53; c.8342_8343delTA; p.lle2781ArgfsX49 and the exon 87; c.11941C>T; p.His3981Tyr substitutions $(n=3)$ share a common haplotype between markers 18xAC and D19S881 (0.56 mB) (black background), and patients harboring the exon 35; c.5726_5727delAG; p.Glu1909GlyfsX39 and the exon 63; c.9242T>C; p.Met3081Thr substitution $(n=2)$ share a common haplotype between markers 18xAC and RYR1_IVS89 (0.27 mB) (black dotted background).

resulting in the expression of both spliced and unspliced transcripts. We therefore hypothesize that the c.103486C>G; p.His3449ins33fsX54/c.14524G>A; p.V4842M genotype determines the phenotype by two interrelated mechanisms, first by reducing the amount of the RyR1 protein, but also the effect of the c.9242T $>$ C; p.V4842M mutant on the residual protein.

\section{Discussion}

Our findings identify RYR1 mutations as a common cause of congenital myopathies with central nuclei and further expand the wide phenotypical spectrum associated with mutations in this gene.

Investigation of the RYR1 gene in our cohort had been prompted by our previous finding of a single heterozygous RYR1 mutation in an isolated case with a diagnosis of $\mathrm{CNM}^{13}$ and the remarkable clinical overlap between genetically unresolved cases with a diagnosis of $\mathrm{CNM}$ and RYR1-related core myopathies with external ophthalmoplegia. ${ }^{10-12}$ In terms of overall severity, our cohort falls between the most severe form of CNM due to mutations in the MTM1 gene ("myotubular myopathy, XLMTM") and mild dominant cases associated with mutations in the DNM2 gene. Although profoundly weak and hypotonic at birth, most patients improved substantially over time. However, one particularly severely affected male (Patient 13) required permanent ventilation and was initially thought to have XLMTM, suggesting that RYR1 mutations ought to be considered in males with similar features once MTMI mutations have been excluded. Cardiac involvement was not present in any of our patients. Although none of our patients had an overt MH reaction, in the absence of IVCT proof to the contrary we consider all patients with RYR1related $\mathrm{CNM}$ at potential $\mathrm{MH}$ risk. It is of note that $\mathrm{MH}$ reactions have been reported previously in a genetically unresolved CNM case, suggesting possible RYRI involvement. ${ }^{21}$

Although considered sufficiently frequent to constitute a diagnosis of $\mathrm{CNM}$, the total number of central nuclei was probably lower than in other genetic forms of 


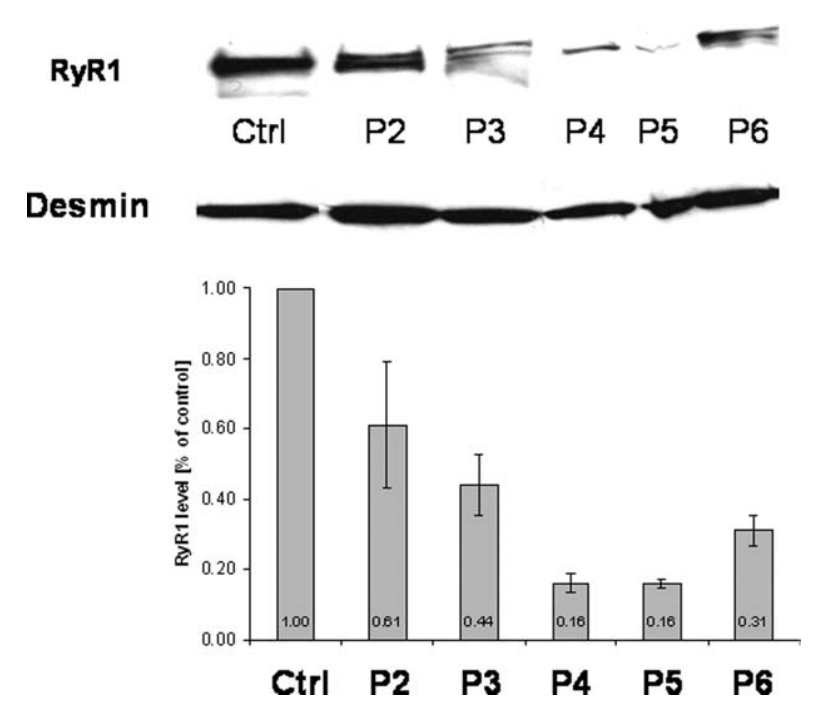

FIGURE 5: Western blot analysis of skeletal muscle tissue from Patients 2-6 compared to a normal control (Ctrl). Protein extracted from muscle biopsies shows a significant reduction of RyR1 expression ( $565 \mathrm{kDa}$ ) compared to the control sample. Desmin immunoreactivity was used as a muscle-specific internal control. Semiquantification using densitometric analyses showed a reduction of RyR 1 protein levels in patients from 16 to $60 \%$ of a normal control.

CNM, and fibers with internal nuclei, often multiple, were a consistent additional finding. The exclusive presence of centralized nuclei as, for example, seen in the most severely affected males with X-linked myotubular myopathy was not a feature in our cohort; this has previously been reported in DNM2-related $\mathrm{CNM}^{6}$ but also more mildly affected males and manifesting carriers with XLMTM. ${ }^{19}$ Most patients had marked increases in fat and connective tissue but other more overtly dystrophic features such as necrosis and regeneration were conspicuously absent. Increases in fat and connective tissue have also been described in other RYR1-related myopathies ${ }^{22}$ and DNM2-related $\mathrm{CNM}^{6}$ but are not a feature in severely affected males with XLMTM. However, this may reflect an age-dependent effect, because similar findings have been documented in older manifesting females. ${ }^{23,24}$ "Necklace" fibers, recently reported in more mildly affected males and manifesting carriers with XLMTM, ${ }^{19}$ were only seen in one patient. Type 1 predominance and hypotrophy with relative type 2 hypertrophy were almost invariable and resembled pathological features seen in congenital fiber type disproportion (CFTD). ${ }^{25}$ Common oxidative enzyme abnormalities comprised central accumulation of stain, but the peripheral halos of reduced oxidative activity characteristic of XLMTM was only seen infrequently, whereas the radial strands characteristic of older patients harboring DNM2 mutations ${ }^{4}$ were generally absent. Despite the marked clinical overlap with RYRI-related core myopathies, the presence of central and internalized nuclei was the main histopathological feature and cores on oxidative enzyme stains were generally not observed at presentation. However, as many patients showed subtle ultrastructural abnormalities, and some patients developed cores on follow-up biopsy, as previously suggested those probably develop with age and indicate RYRI involvement. ${ }^{26}$

Although the diagnosis of "centronuclear myopathy" was unequivocally established by an experienced pathologist in each case at presentation, the common occurrence of central and often multiple internalized nuclei as well as evolution of cores over time raises the difficult question of boundaries between specific congenital myopathies and resulting problems of nomenclature. Also in line with recent work on CNM as a "widening concept," ${ }^{27}$ we propose the term "congenital myopathies with central nuclei" as a more accurate description of the entity described in this study, emphasizing central nuclei as the defining histopathological feature, while implicitly acknowledging the presence of additional findings such as multiple and internalized nuclei. Interestingly, it is of note that some CNM patients described before the genetic resolution of the condition (including, notably, the original patient reported by Spiro et $\mathrm{al}^{3}$ ) shared more clinicopathological features with the entity described in this study than with other genetic forms of CNM, indicating that they may have had a similar genetic background.

The majority of our patients had a genetic background characterized by compound heterozygosity for one mutation expected to result in a reduced RyR1 protein and an allelic heterozygous $R Y R 1$ missense mutations, as previously reported in other RYRI-related myopathies. ${ }^{11,28,29}$ Although most cases were compatible with recessive inheritance, three patients with identical clinical features had only one single heterozygous $R Y R I$ mutation inherited from an asymptomatic parent. The significance of these findings is uncertain, but possible explanations include an allelic large $R Y R 1$ intragenic dele$\operatorname{tion}^{30}$ not identifiable with the applied techniques, other copy number variations, promoter mutations or digeny for the RYR1 mutation identified, and a mutation in a functionally related gene. In contrast to CCD due to heterozygous dominant $R Y R 1$, no mutational hotspots were identified. Unexpectedly, we found three recurrent RYRI haplotypes in the South African cohort, suggesting the presence of founder effects in this population, in keeping with a substantial number of earlier reports of $\mathrm{CNM}^{31}$ and other RYR1-related phenotypes in South Africa. ${ }^{32-35}$ Probably due to this founder effect, congenital myopathy with central nuclei appears to be the most common form of congenital myopathy at the Western Cape, at variance 
with its relatively low incidence in other populations. Recurrent mutations in the South African population have been reported for other conditions such as cystic fibrosis $^{36}$ and galactosemia. ${ }^{37}$

Our findings raise the question of molecular mechanisms common to RYRI-related congenital myopathy with central nuclei and other forms of CNM with distinct genetic backgrounds. The three major genes previously implicated in different forms of CNM-MTM1, $B I N 1$, and DNM2 - are intricately linked to different aspects of membrane trafficking and endocytosis and a functional link to RYR1, encoding the principal sarcoplasmic reticulum calcium release channel (RyR1) with a crucial role in excitation-contraction coupling (ECC), is not immediately apparent. However, recent findings indicate a role of the myotubularin-amphiphysindynamin pathway in the assembly of T-tubules and other structural components of the ECC machinery, ${ }^{38-42}$ as well as the possibility of phosphoinositide-mediated mechanisms of ion channel regulation, ${ }^{43,44}$ suggesting potential molecular links. In addition, specific defects of T-tubule and Ryr 1 receptor assembly in particular have been documented in two animal models of myotubular myopathy. ${ }^{14,15}$ Regardless of mechanism, however, our study identifies RYRI as a significant contributor to the pathogenesis of congenital myopathies with central nuclei. In addition, supported by emerging data demonstrating a direct link between other CNM gene products and the regulation of T-tubule/SR structure and function, our findings suggest disturbance of the excitationcontraction coupling machinery as a principal molecular mechanism in various forms of congenital myopathies with central nuclei or, indeed, the congenital myopathies as a group.

\section{Acknowledgments}

Part of this work was supported by a grant from the Guy's and St Thomas' Charitable Foundation to H.J. (Grant number 070404) and of the Muscular Dystrophy Association (MDA) of the USA to F.M. (Grant number 68762). Supported also by the National Commissioning Group (NCG) of the United Kingdom to the Dubowitz Neuromuscular Centre and Guy's Hospital.

The authors thank the late Professor Colin SinclairSmith, former Head of the Histopathology Department at the University of Cape Town, who died in October 2008 and devoted many hours to the study of the histopathological findings of children with neuromuscular disease from South Africa; he assisted with the early identification of the South African patients described in this article. We thank our patients and their families for their participation.

\section{Potential Conflicts of Interest}

Nothing to report.

\section{References}

1. Jungbluth $H$, Wallgren-Pettersson C, Laporte J. Centronuclear (myotubular) myopathy. Orphanet J Rare Dis 2008;3:26.

2. Laporte J, Hu LJ, Kretz C, et al. A gene mutated in X-linked myotubular myopathy defines a new putative tyrosine phosphatase family conserved in yeast. Nat Genet 1996;13:175-182.

3. Spiro AJ, Shy GM, Gonatas NK. Myotubular myopathy. Arch Neurol 1966;14:1-14

4. Bitoun M, Maugenre S, Jeannet PY, et al. Mutations in dynamin 2 cause dominant centronuclear myopathy. Nat Genet 2005;37:1207-1209.

5. Bitoun M, Bevilacqua JA, Prudhon B, et al. Dynamin 2 mutations cause sporadic centronuclear myopathy with neonatal onset. Ann Neurol 2007;62:666-670.

6. SchessI J, Medne L, Hu Y, et al. MRI in DNM2-related centronuclear myopathy: evidence for highly selective muscle involvement. Neuromuscul Disord 2007;17:28-32.

7. Nicot AS, Toussaint A, Tosch $V$, et al. Mutations in amphiphysin 2 (BIN1) disrupt interaction with dynamin 2 and cause autosomal recessive centronuclear myopathy. Nat Genet 2007;39:1134-1139.

8. Jeannet PY, Bassez G, Eymard B, et al. Clinical and histologic findings in autosomal centronuclear myopathy. Neurology 2004; 62:1484-1490.

9. Treves $S$, Anderson AA, Ducreux $S$, et al. Ryanodine receptor 1 mutations, dysregulation of calcium homeostasis and neuromuscular disorders. Neuromuscul Disord 2005;15:577-587.

10. Monnier N, Ferreiro A, Marty I, et al. A homozygous splicing mutation causing a depletion of skeletal muscle RYR1 is associated with multi-minicore disease congenital myopathy with ophthalmoplegia. Hum Mol Genet 2003;12:1171-1178.

11. Monnier N, Marty I, Faure J, et al. Null mutations causing depletion of the type 1 ryanodine receptor (RYR1) are commonly associated with recessive structural congenital myopathies with cores. Hum Mutat 2008;29:670-678.

12. Jungbluth $H$, Zhou $H$, Hartley $L$, et al. Minicore myopathy with ophthalmoplegia caused by mutations in the ryanodine receptor type 1 gene. Neurology 2005;65:1930-1935.

13. Jungbluth $H$, Zhou $H$, Sewry $C A$, et al. Centronuclear myopathy due to a de novo dominant mutation in the skeletal muscle ryanodine receptor (RYR1) gene. Neuromuscul Disord 2007;17:338-345.

14. Dowling JJ, Vreede AP, Low SE, et al. Loss of myotubularin function results in T-tubule disorganization in zebrafish and human myotubular myopathy. PLoS Genet 2009;5:1000372.

15. Al-Qusairi L, Weiss N, Toussaint $A$, et al. T-tubule disorganization and defective excitation-contraction coupling in muscle fibers lacking myotubularin lipid phosphatase. Proc Natl Acad Sci U S A 2009;106:18763-18768.

16. Laing NG, Clarke NF, Dye DE, et al. Actin mutations are one cause of congenital fiber type disproportion. Ann Neurol 2004;56:689-694.

17. Clarke NF, Kolski H, Dye DE, et al. Mutations in TPM3 are a common cause of congenital fiber type disproportion. Ann Neurol 2008;63:329-337.

18. Zhou H, Lillis S, Loy RE, et al. Multi-minicore Disease and atypical periodic paralysis associated with novel mutations in the skeletal muscle ryanodine receptor (RYR1) gene. Neuromuscul Disord 2010;20:166-173.

19. Bevilacqua JA, Bitoun M, Biancalana V, et al. "Necklace" fibers, a new histological marker of late-onset MTM1-related centronuclear myopathy. Acta Neuropathol 2009;117:283-291. 
20. Robinson R, Carpenter D, Shaw MA, et al. Mutations in RYR1 in malignant hyperthermia and central core disease. Hum Mutat 2006;27:977-989

21. Quinn RD, Pae WE, McGary SA, et al. Development of malignant hyperthermia during mitral valve replacement. Ann Thorac Surg 1992;53:1114-1116.

22. Dubowitz V, Sewry CA. Muscle biopsy - a practical approach. 3rd ed. London: Saunders, 2007.

23. Jungbluth $H$, Sewry CA, Buj-Bello A, et al. Early and severe presentation of $\mathrm{X}$-linked myotubular myopathy in a girl with skewed X-inactivation. Neuromuscul Disord 2003;13:55-59.

24. Schara U, Kress W, Tucke J, et al. X-linked myotubular myopathy in a female infant caused by a new MTM1 gene mutation. Neurology 2003;60:1363-1365.

25. Clarke NF, North KN. Congenital fiber type disproportion - 30 years on. J Neuropathol Exp Neurol 2003;62:977-989.

26. Quinlivan RM, Muller CR, Davis $M$, et al. Central core disease: clinical, pathological, and genetic features. Arch Dis Child 2003; 88:1051-1055.

27. Romero NB. Centronuclear myopathies: a widening concept. Neuromuscul Disord 2010;20:223-228.

28. Zhou $\mathrm{H}$, Jungbluth $\mathrm{H}$, Sewry $\mathrm{CA}$, et al. Molecular mechanisms and phenotypic variation in RYR1-related congenital myopathies. Brain 2007;130:2024-2036

29. Zhou $H$, Brockington $M$, Jungbluth $H$, et al. Epigenetic allele silencing unveils recessive RYR1 mutations in core myopathies. Am J Hum Genet 2006;79:859-868.

30. Monnier N, Laquerriere A, Marret $\mathrm{S}$, et al. First genomic rearrangement of the RYR1 gene associated with an atypical presentation of lethal neonatal hypotonia. Neuromuscul Disord 2009;19: 680-684.

31. Isaacs H, Badenhorst ME. Centronuclear myopathy - an inherited neuromuscular disorder. A report of 3 cases. S Afr Med J 1991; 80:247-250.

32. Isaacs $\mathrm{H}$, Heffron JJ, Badenhorst M. 'Picture framé fibres in a carrier of the trait for malignant hyperpyrexia. S Afr Med J 1975;49: 1923-1926.

33. Isaacs H, Badenhorst ME. Multicore disease. S Afr Med J 1980;57: 543-546.
34. Isaacs $\mathrm{H}$, Heffron JJ, Badenhorst M. Central core disease. A correlated genetic, histochemical, ultramicroscopic, and biochemical study. J Neurol Neurosurg Psychiatry 1975;38: 1177-1186.

35. Isaacs $H$, Badenhorst ME. Dominantly inherited malignant hyperthermia $(\mathrm{MH})$ in the King-Denborough syndrome. Muscle Nerve 1992;15:740-742.

36. Goldman A, Labrum R, Claustres $M$, et al. The molecular basis of cystic fibrosis in South Africa. Clin Genet 2001;59:37-41.

37. Henderson HE, Leisegang F, Brown R, et al. The clinical and molecular spectrum of galactosaemia in patients from the Cape Town region of South Africa. BMC Pediatr. 2002;2:7.

38. Butler MH, David C, Ochoa GC, et al. Amphiphysin II (SH3P9; BIN1), a member of the amphiphysin/Rvs family, is concentrated in the cortical cytomatrix of axon initial segments and nodes of ranvier in brain and around $\mathrm{T}$ tubules in skeletal muscle. J Cell Biol 1997;137:1355-1367.

39. Lee E, Marcucci M, Daniell L, et al. Amphiphysin 2 (Bin1) and T-tubule biogenesis in muscle. Science 2002;297: 1193-1196.

40. Razzaq A, Robinson IM, McMahon HT, et al. Amphiphysin is necessary for organization of the excitation-contraction coupling machinery of muscles, but not for synaptic vesicle endocytosis in Drosophila. Genes Dev 2001;15:2967-2979.

41. Buj-Bello A, Laugel V, Messadeq N, et al. The lipid phosphatase myotubularin is essential for skeletal muscle maintenance but not for myogenesis in mice. Proc Natl Acad Sci U S A 2002;99: 15060-15065.

42. Buj-Bello A, Fougerousse F, Schwab Y, et al. AAV-mediated intramuscular delivery of myotubularin corrects the myotubular myopathy phenotype in targeted murine muscle and suggests a function in plasma membrane homeostasis. Hum Mol Genet 2008;17: 2132-2143.

43. Laporte J, Bedez F, Bolino A, et al. Myotubularins, a large disease-associated family of cooperating catalytically active and inactive phosphoinositides phosphatases. Hum Mol Genet 2003; 12(Spec No 2):R285-292.

44. Shen J, Yu WM, Brotto M, et al. Deficiency of MIP/MTMR14 phosphatase induces a muscle disorder by disrupting $\mathrm{Ca}(2+)$ homeostasis. Nat Cell Biol 2009;11:769-776. 